Pure Appl. Chem., Vol. 76, No. 5, pp. 997-1005, 2004.

(C) 2004 IUPAC

\title{
Development of modulators of multidrug resistance: A pharmacoinformatic approach*
}

\author{
Gerhard F. Ecker ${ }^{1, \ddagger}$ and Peter Chiba ${ }^{2}$ \\ ${ }^{1}$ Department of Pharmaceutical Chemistry, University of Vienna, Althanstrasse 14, \\ 1090 Wien, Austria; ${ }^{2}$ Department of Medical Chemistry, Medical University of \\ Vienna, Waehringer Strasse 10, 1090 Wien, Austria
}

\begin{abstract}
Inhibition of drug efflux pumps such as P-glycoprotein represents a versatile approach for overcoming multidrug resistance in tumor therapy. Although numerous compounds have been identified as being able to inhibit P-glycoprotein, only little is known on the molecular basis of the drug-protein interaction. This article gives an overview of the different pharmacoinformatic approaches we used to develop new propafenone-type modulators of P-glycoprotein. These include 2D- and 3D-QSAR studies, artificial neural networks, and photoaffinity labeling studies.
\end{abstract}

\section{INTRODUCTION}

In industrialized countries, tumors are number two in the causes of death. Although enormous progress has been achieved in the field of tumor therapy (e.g., Imatinib), only approximately $50 \%$ of all tumors are susceptible to chemotherapy. Out of these, by far more than $50 \%$ rapidly develop resistance during therapy. Most often, this is a multiple drug resistance caused by overexpression of P-glycoprotein (P-gp). P-gp is a membrane-bound efflux pump which was shown by Ling and coworker to transport a wide variety of anticancer agents (vinca alkaloids, anthracyclines, epipodophyllotoxines, taxanes, actinomycine D) out of tumor cells [1]. It is a $170 \mathrm{kD}$ protein showing two transmembrane domains and 2 ATP-binding sites. P-gp functions is an ATP-dependent xenotoxin transport pump which leads to a decrease of intracellular concentrations of cytotoxic agents [2].

In 1981, Tsuruo et al. identified verapamil as being able to block P-gp-mediated transport of cytotoxic agents [3]. Inhibition of P-gp leads to a resensitization of multidrug-resistant tumor cells and thus seems to be a promising approach for overcoming multiple drug resistance in tumor therapy. Within the past 20 years, numerous compounds were identified as being able to block P-gp-mediated drug transport. These include protein kinase $\mathrm{C}$ inhibitors (calphostin $\mathrm{C}$, staurosporine), calmodulin antagonists (fliphenazin, trifluoperazin, flupenthixol), cyclic peptides (cyclosporin A, valspodar, FK 506, rapamycin) and ion channel blockers, such as amiodaron, verapami, and niguldipine [4]. We identified the class Ic antiarrhythmic agent propafenone (Fig. 1) as medium active P-gp inhibitor [5]. This article gives an overview of our studies on propafenone-type modulators of multidrug resistance.

\footnotetext{
*Lecture presented at the Polish-Austrian-German-Hungarian-Italian Joint Meeting on Medicinal Chemistry, Kraków, Poland, 15-18 October 2003. Other presentations are published in this issue, pp. 907-1032.

${ }^{\ddagger}$ Corresponding author
} 


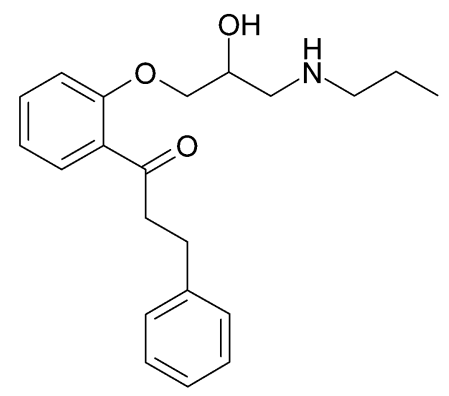

Fig. 1 Chemical structure of propafenone.

\section{LIGAND-BASED DRUG DESIGN}

Propafenone has several advantages when used in a drug design approach.

It is easy to synthesize (Fig. 2) and thus enables broad structural variations. Additionally, it comprises several substructures that were identified by Klopman et al. as being beneficial for high P-gp inhibitory activity [6]. These include two aromatic rings, a carbonyl group, and a basic nitrogen atom. However, its disadvantages are its high conformational flexibility (10 rotable bonds) and its antiarrhythmic potency.<smiles>[R1]C(=O)c1ccccc1O</smiles><smiles>[R]C(=O)c1ccccc1OCC1CO1</smiles><smiles>[R1]C(=O)c1ccccc1OCC(O)CN([R1])[R]</smiles>

Fig. 2 General scheme for synthesis of propafenone derivatives: (i) $\mathrm{NaOH}$, epichlorohydrine; (ii) amine/methanol.

One of the most important prerequisites when running a lead optimization program is a suitable system for measuring the pharmacological activity of the compounds under consideration. Although several assays are published (cell cytotoxicity assay, calcein AM uptake, rhodamine 123 efflux, etc.), we developed a daunomycine-based efflux assay, which gives a direct measure for P-gp inhibition and shows high reproducibility [7]. CCRF-CEM vcr 1000 cells are loaded with the fluorescent toxin daunomycine, and the cell-associated fluorescence is measured vs. time. The experiment is repeated using at least six different concentrations of modulator (Fig. 3a). Subsequently, first-order rate constants are calculated for each experiment and dose-response curves are obtained via a plot of rate constant vs. modulator concentration (Fig. 3b). This enables calculation of $\mathrm{EC}_{50}$ values of the respective modulators. 


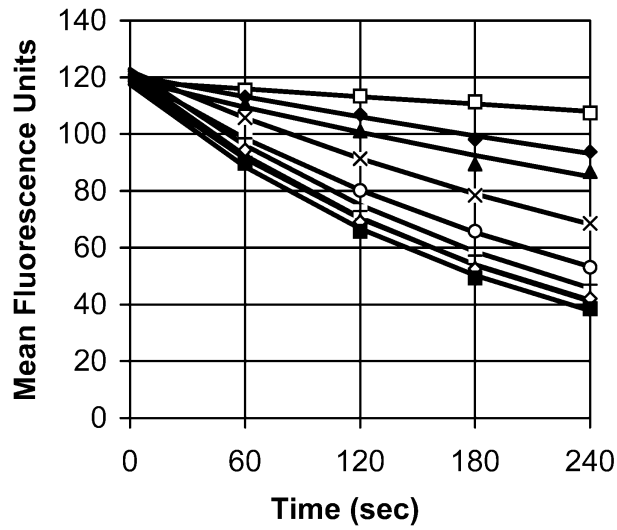

Fig. 3a Plot of fluorescence vs. time of P-gp-expressing cells preloaded with daunorubicin. The lines represent different concentrations of modulator.

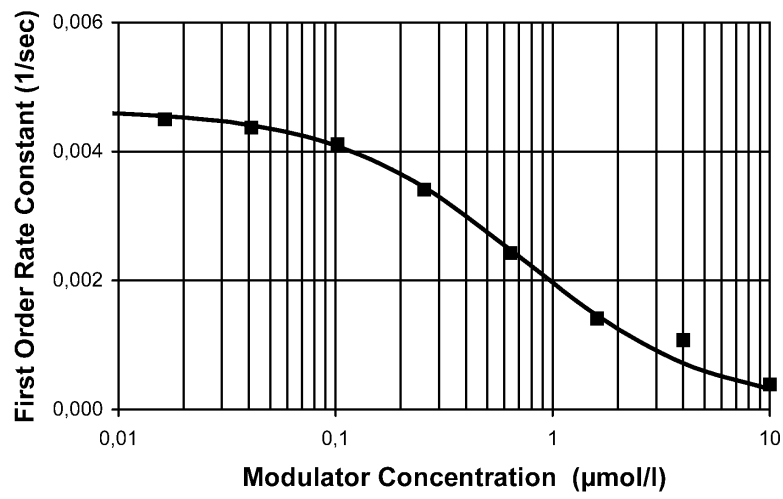

Fig. 3b Plot of first-order rate constant vs. modulator concentration as obtained from experiments shown in Fig. 3a.

\section{D-QSAR studies}

On the basis of more than 150 propafenone-type compounds, Hansch analyses, Free-Wilson analyses, and the Topliss approach were applied. The results are presented in Fig. 4 and showed that

- within homologous series of compounds, pharmacological activity is strongly related to overall lipophilicity of the compounds [8];

- $\quad$ the carbonyl group acts as H-bond acceptor [9];

- $\quad$ substituents on the aromatic rings influence activity mainly via their sigma-values [10] (electronic contribution rather than lipophilic one);

- $\quad$ substituents on the nitrogen atom should be highly lipophilic, but not too voluminous [11];

- $\quad$ the nitrogen atom interacts as H-bond acceptor and thus does not need to be a chargable (amide) [12]; and

- the optimal distance between the central aromatic ring system and the nitrogen atom is in the range of 3 to 4 methylene groups [13]. 


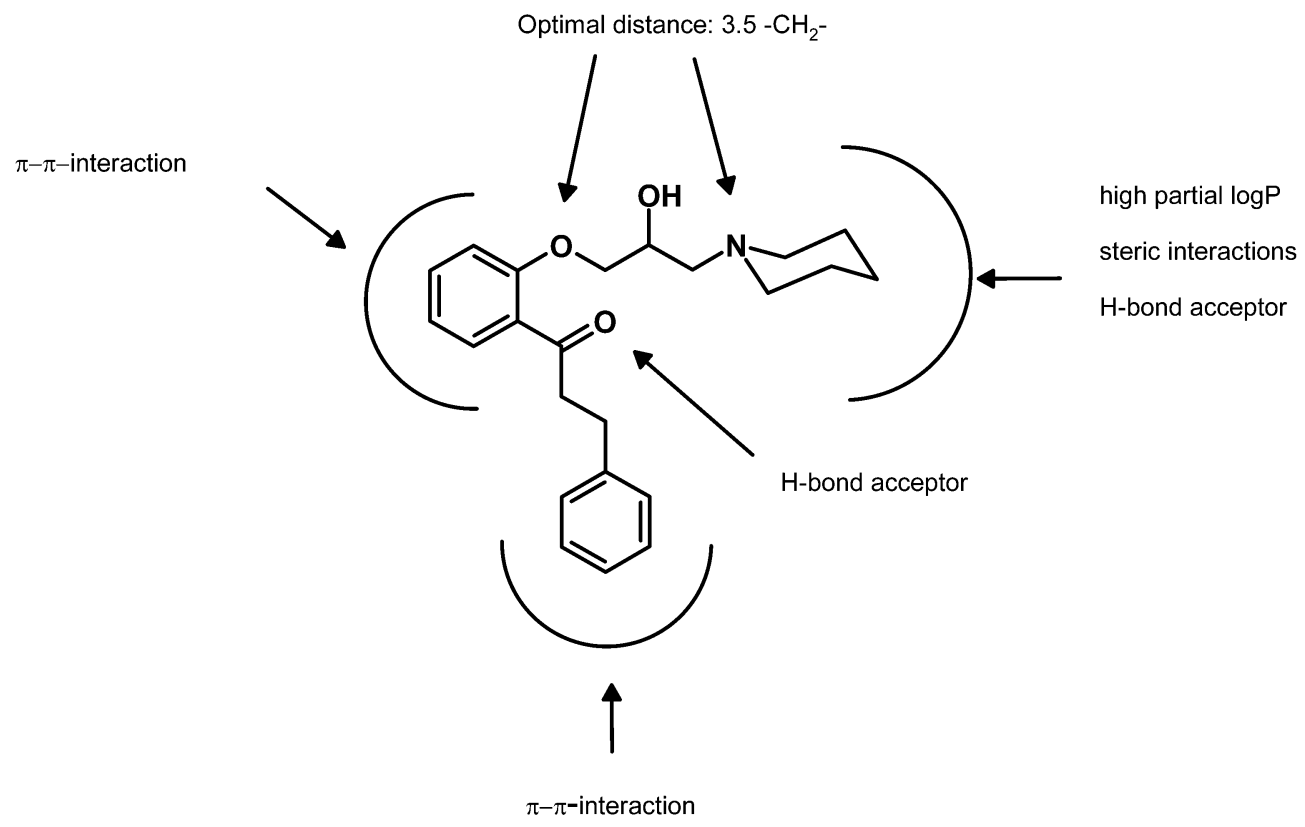

Fig. 4 Summary of the results of SAR studies on propafenone-type inhibitors of P-gp.

\section{D-QSAR studies}

CoMFA and CoMSIA studies were also performed, and the results supported the findings obtained by $2 \mathrm{D}$ approaches. The alignment used is based on an overlay of the central aromatic ring, the carbonyl group, and the nitrogen atom (Fig. 5). Molecular interaction fields obtained indicate that there are both steric favorable (in line of the hydroxypropylamino chain) and steric unfavorable regions (orthogonal to the hydroxypropylamino chain) in the vicinity of the nitrogen atom. This supports results from Pajeva and Wiese, who also identified lipophilicity as a space-directed property in a 3D-QSAR study of selected propafenone derivatives [14].

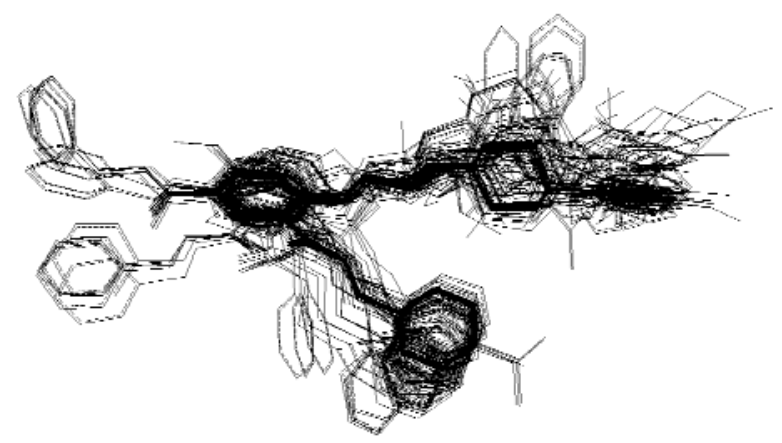

Fig. 5 Alignment of 131 propafenone analogs used for CoMFA and CoMSIA studies.

\section{IDENTIFICATION OF NEW LEAD COMPOUNDS}

Although numerous compounds were identified in the past as being able to inhibit $\mathrm{P}$-gp, there is a strong demand for structurally new lead compounds. Most of the compounds identified up to now are well-established drugs in other therapeutic areas. Thus, these substances were already optimized for a given biological target, and their original pharmacological activity often gives rise to serious side-effects [15]. 
For identification of new lead compounds in the field, we applied two different approaches: chemical function-based pharmacophoric feature modeling and artificial neural networks.

\section{Chemical function-based pharmacophoric feature modeling}

The CATALYST software package enables assignment of pharmacophic features, such as hydrophobic, aromatic, H-bond donor, H-bond acceptor, positive ionizable, to substructures of the molecules under investigation. Thus, a training set of 10-15 highly active compounds is generated and the corresponding features are assigned. Then, a multiconformational database is generated and a 3D-arrangement of the pharmacophoric features fitting all compounds of the training set is searched for. If found, this so-called "hypothesis" may then be used for virtual screening of compound libraries.

We used a set of 27 structurally diverse, propafenone-type inhibitors of P-gp to generate a pharmacophore hypothesis for P-gp inhibitors. The best hypothesis found included one hydrophobic feature, two hydrophobic-aromatic features, one H-bond donor, and one positively ionizable feature. This hypothesis was used for a virtual screen of the World Drug Index for new P-gp ligands. This resulted in 232 hits, which, after refinement of the model, were reduced to 28 . A literature survey showed that 9 out of those 28 compounds have previously been described as P-gp inhibitors (Fig. 6), which supports the validity of the model [16].<smiles>[R16][R15]([R15])([H])[H]</smiles><smiles>CC(C)(C)c1ccc(C(O)CCCN2CCC(C(O)(c3ccccc3)c3ccccc3)CC2)cc1</smiles><smiles>COC(=O)C1=C(C)NC(C)=C(C(=O)OC2CCCN(Cc3ccccc3)C2)C1c1cccc([N+](=O)[O-])c1</smiles><smiles>OCc1cc(C(O)CNCCCCCCCc2ccccc2)ccc1O</smiles><smiles>OC(COc1cccc2ncccc12)CN1CCN(C2c3ccccc3CCc3ccccc32)CC1</smiles><smiles>N#CC(COc1cccc2ncccc12)CN1CCN(C2c3ccccc3CCc3ccccc32)CC1</smiles>

CP-215548

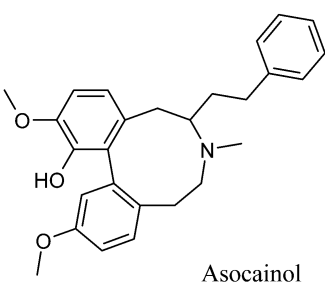<smiles>OCCN1CCCN(CCCN2c3ccccc3Sc3ccc(C(F)(F)F)cc32)CC1</smiles><smiles>CCN(CC)CCCC(C)Nc1c2ccc(Cl)cc2nc2ccc(OC)cc12</smiles>

Fig. 6 Chemical structure of the compounds identified in a virtual screen of the world drug index based on a 3D-pharmacophore model derived with CATALYST. 


\section{Self-organizing maps for lead identification}

Artificial neural networks represent a versatile tool for modeling abstract and complex relationships. Thus, their use gains increasing interest in the drug design field. On principal, the methods available may be divided into algorithms using supervised or nonsupervised learning routines. Amongst the latter, self-organizing maps (SOMs) are most widely used. Simply put, the compounds are arranged on a map according to their similarity. If the descriptors used for encoding the chemical structures also reflect biological properties, compounds very often are grouped in active and inactive ones. For our approach, a set of 131 propafenone-type modulators of MDR was used as training set for an SOM. Autocorrelation vectors on basis of 3 different atomic properties for distances of 0-10 bonds were calculated using the software package PETRA and served as descriptors for the respective compounds. This set-up resulted in a remarkably good separation of active and inactive propafenones [17]. In the next step, the map was enlarged, the propafenone training set was merged with the SPECS compound library, and the whole dataset was presented to the SOM under identical training conditions. If the SOM is indeed able to separate highly active from inactive compounds, derivatives from the SPECS library co-localizing with highly active propafenones should also exhibit high activity. Out of more than 150000 compounds from the SPECS library, 12 compounds co-localized with the most active propafenones GPV 576 and GPV 610. Some of these virtual screening hits show high structural analogy, which further reduced the number of hits to 7 . These compounds were subject to pharmacological testing in our daunorubicin efflux assay. Two out of these 7 hits showed $\mathrm{EC}_{50}$ values lower than $1 \mu \mathrm{M}$ (Fig. 7), 4 compounds exhibited $\mathrm{EC}_{50}$ values between 1 and $10 \mu \mathrm{M}$, and only 1 compound was inactive. In a validation run, 8 SPECS derivatives co-localizing with low active propafenones were tested. Only 1 compound showed an acceptable $\mathrm{EC}_{50}$ value $(17 \mu \mathrm{M})$, the remaining ones were almost inactive $\left(\mathrm{EC}_{50}>100 \mu \mathrm{M}\right)$. Thus, this procedure is excellently suited for identification of structurally new hits in virtual screens of medium-sized compound libraries.
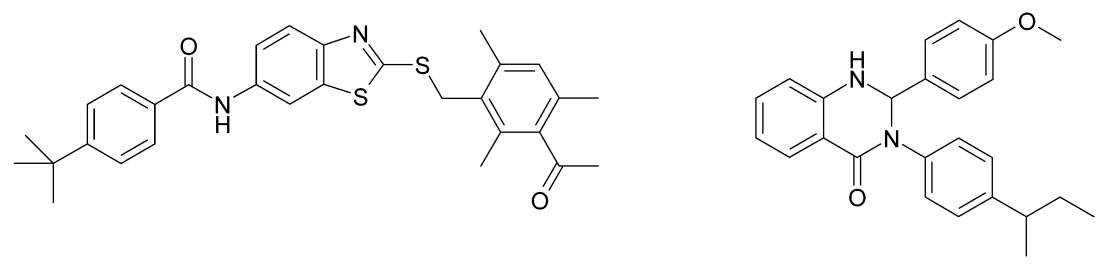

Fig. 7 Hits obtained via an in silico screen of the SPECS library using self-organizing maps.

\section{PHOTOAFFINITY LABELING WITH BENZOPHENONE ANALOGS}

To complement our intensive ligand-based modeling approaches with structural data, we used benzophenone analogs for photoaffinity labeling studies. Benzophenones represent a versatile tool for the characterization of the "propafenone-site" on P-gp. The structural modification that is necessary to render a propafenone a benzophenone analog (Fig. 8) is rather small and does not influence the pharmacological profile of the compounds. Thus, a set of benzophenones showed an SAR pattern similar to propafenones. 
<smiles>[R]N([R])CC(O)COc1ccccc1C(=O)c1ccccc1</smiles>

Benzophenone Analogue<smiles>COC(CCc1ccccc1)c1ccccc1OCC(O)CN1CCCCC1</smiles>

Fig. 8 Chemical structure of benzophenones used for photoaffinity labeling and of the non-photoactivatable propafenone derivative GPV 090.

Competition experiments with the non-photoactivatable propafenone derivative GPV 090 (Fig. 9) demonstrated that benzophenones and propafenones indeed target the same binding site.

Last but not least, the photoactivation takes place on the carbonyl group, which was identified as a pharmacophoric substructure in our previous studies. After irradiation of P-gp-enriched membrane vesicles in presence of the photoligand, the protein was purified and enzymatically digested. Peptide fragments were identified via MALDI-TOF mass spectrometry and compared to fragment masses obtained in an in silico digestion of the protein. This enabled the identification of labeled fragments. The use of four different benzophenone analogs allowed the assignment of consensus labeling regions and thus enabled separation of specific from nonspecific binding sites. As shown in Fig. 9, labeling mainly occurs in transmembrane helices $3,5,6,8,9,11$, and 12 . Additionally, one nucleotide binding domain is also labeled [18]. Currently, this approach is extended to analyze the labeling pattern during different steps of the catalytic cycle of P-gp.

\section{3 out of 4 ligands binding}

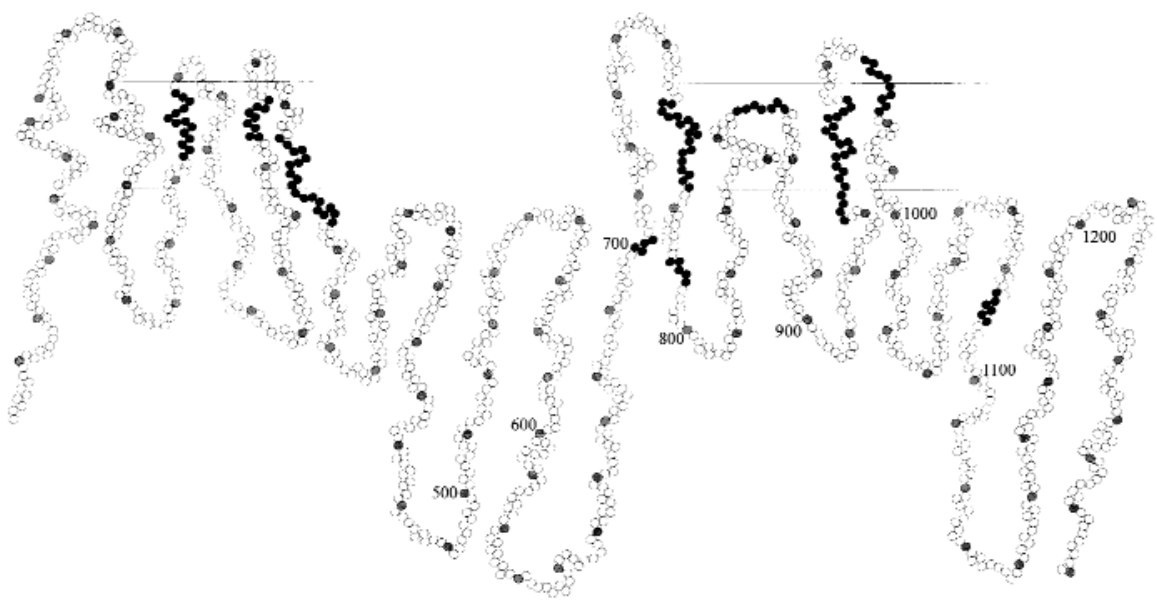

Fig. 9 Consensus labeling regions obtained by combining the results from three out of four ligands. 


\section{OUTLOOK}

Within the past year, X-ray crystallographic structures of three bacterial ABC-transporters were published in the literature. These include the structure of the lipid A exporter MsbA [19], the vitamin B12 importer BtuCD [20] (both from E. coli), and the MsbA from V. colerae [21]. These structures served as starting points for protein homology modeling approaches aiming at 3D-models of P-gp [22,23]. Additionally, extensive structural studies of the nucleotide binding domains combined with molecular modeling and molecular dynamics simulations give first insights into functional aspects, especially the coupling of ATP-binding to movement of the transmembrane domain. In cooperation with the groups of W. Konings and R. Pellicciari, we started extensive structural studies on the bacterial ABC-transporter LmrA (a structural and functional homolog of P-gp) combining ligand-based drug design, photoaffinity labeling, and protein homology modeling. These studies should enable deeper insights into the molecular basis of P-gp-mediated drug transport and thus increase our knowledge of the structure and function of $\mathrm{ABC}$-transporters in general.

\section{ACKNOWLEDGMENT}

We gratefully acknowledge financial support provided by the Austrian Science Fund (grant \# P13851MOB)

\section{REFERENCES}

1. R. L. Juliano and V. Ling. Biochim. Biophys. Acta 455, 152 (1976).

2. M. M. Gottesman and I. Pastan. Annu. Rev. Biochem. 62, 385 (1993).

3. T. Tsuruo, H. Iida, S. Tsukagoshi, Y. Sakurai. Cancer Res. 41, 1967 (1981).

4. C. Avendano and J. C. Menendez. Curr. Med. Chem. 9, 159 (2002).

5. P. Chiba, S. Burghofer, E. Richter, B. Tell, A. Moser, G. Ecker. J. Med. Chem. 38, 2789 (1995).

6. G. Klopman, L. M. Shi, A. Ramu. Mol. Pharmacol. 52, 323 (1997).

7. P. Chiba, W. Holzer, M. Landau, G. Bechmann, K. Lorenz, B. Plagens, M. Hitzler, E. Richter, G. Ecker. J. Med. Chem. 41, 4001 (1998).

8. G. Ecker, P. Chiba, M. Hitzler, D. Schmid, K. Visser, H. P. Cordes, J. Csöllei, J. K. Seydel, K.-J. Schaper. J. Med. Chem. 39, 4767 (1996).

9. P. Chiba, G. Ecker, D. Schmid, J. Drach, B. Tell, S. Goldenberg, V. Gekeler. Mol. Pharmacol. 49, 1122 (1996).

10. C. Tmej, E. Richter, M. Hitzler, P. Chiba, G. Ecker, W. Fleischhacker. J. Pharm. Pharmacol. 49 (Suppl. 4), 176 (1997).

11. P. Chiba, M. Hitzler, E. Richter, M. Huber, C. Tmej, G. Ecker. Quant. Struct.-Act. Rel. 16, 361 (1997).

12. G. Ecker, M. Huber, D. Schmid, P. Chiba. Mol. Pharmacol. 56, 791 (1999).

13. P. Chiba, D. Annibali, M. Hitzler, E. Richter, G. Ecker. Il Farmaco 53, 357 (1998).

14. I. K. Pajeva and M. Wiese. Quant. Struct.-Act. Relat. 17, 301 (1998).

15. M. Raderer and W. Scheithauer. Cancer 72, 3553 (1993).

16. C. Klein, D. Kaiser, S. Kopp, P. Chiba, G. F. Ecker. J. Comput. Aided Mol. Drug Des. 16, 785 (2002).

17. D. Kaiser, P. Chiba, G. F. Ecker. Proc. of the XVIth International Symposium on Medicinal Chemistry, Bologna (2002).

18. G. F. Ecker, E. Csaszar, S. Kopp, B. Plagens, W. Holzer, W. Ernst, P. Chiba. Mol. Pharmacol. 61, 637 (2002).

19. G. Chang and C. B. Roth. Science 293, 1793 (2001).

20. K. P. Locher, A. T. Lee, D. C. Rees. Science 296, 1091 (2002). 
21. G. Chang. J. Mol. Biol. 330, 419 (2003).

22. M. Seigneuret and A. Garnier-Suillerot. J. Biol. Chem. 278, 30115 (2003).

23. D. R. Stenham, J. D. Campbell, M. S. Sansom, C. F. Higgins, I. D. Kerr, K. J. Linto. FASEB J. 17, 2287 (2003). 